\title{
Potential Role of Dimers in Oncology
}

\author{
S Satish Kumar ${ }^{1}$, Sreena N Sreedharan ${ }^{2}$, Shankargouda Patil ${ }^{3}$, A Thirumal Raj $^{4}$
}

World Journal of Dentistry, (2019): 10.5005/jp-journals-10015-1608

\section{INTRODUCTION}

D ynamic protein-protein interactions play a key role in biological regulatory networks. The proteins responsible for cellular proliferation and differentiation are homodimers or heterodimers. Dimerization is a key step by which they get activated in signal transduction pathways. The human genome contains 58 receptortype tyrosine kinases (RTKs) and 32 non-receptor types which are essential components of signal transduction pathways. ${ }^{1}$ These receptor tyrosine kinases catalyze the transfer of a single phosphoryl group from ATP and play an important role in cellular growth and differentiation. Extracellular ligand binding induces or stabilizes receptor dimerization, resulting in receptor tyrosine kinase activity. ${ }^{2}$ Cellular signaling through receptor tyrosine kinase mediation is tightly controlled and coordinated in normal cells. Deregulation of the RTK signaling system causes aberrations in kinase activity, which results in enhanced signaling capacity and malignant transformation. The signal transducers and activator of transcription (STAT) family of proteins are emerging target for the development of antitumor agents. In normal cells, STAT activation is tightly controlled, but constitutive STAT ${ }^{3}$ activity results in deregulated growth and angiogenesis resulting in malignancy. Direct disruption of dimerization in the STAT signaling cascade has been shown to induce transformed cell death and tumor regression. ${ }^{3,4}$

Microtubules are heterodimeric polymers of $a$ and $\beta$ tubulin arranged along a cylindrical axis. They are a major structural component of the cytoskeleton maintaining cell shape and polarity. During the cell cycle, microtubules form the mitotic spindle to align replicated chromosomes and mediate segregation of chromosomes into daughter cells. In malignant cells, apoptosis is induced through a cell cycle block at the M-phase. The cell cycle block is induced by the drugs interacting with the microtubules acting as spindle poison. ${ }^{5,6}$ The dynamic heterodimeric nature of microtubules and the clinical success of microtubule stabilizers/ destabilizers suggest they will continue to be an important target for the development of anticancer therapeutics. ${ }^{7}$ The dimeric compound has the ability to bind to a receptor at two separate binding sites or two monomeric sites of a dimeric protein. Thus they are the ideal material to be formulated as drug compounds. Functional diversity can be noted within the members of a single protein family if the regulatory dimerization properties vary with different combinations of proteins. These regulatory mechanisms aid in achieving several biological outcomes including enhanced orientation and proximity, special and temporal boundary generation, specificity enhancement, regulation of the transition from monomer to dimer, and heterodimerization differential regulation. ${ }^{8}$ Cancer chemotherapeutic targets including signaling proteins, microtubules, topoisomerases, and DNA are dimeric
${ }^{1}$ Sai Srinivas Dental Care, Chennai, Tamil Nadu, India

${ }^{2}$ Corning Dental Associates, Corning, New York, USA

${ }^{3}$ Department of Maxillofacial Surgery and Diagnostic Sciences, Division of Oral Pathology, College of Dentistry, Jazan University, Jazan, Kingdom of Saudi Arabia

${ }^{4}$ Department of Oral Pathology and Microbiology, Sri Venkateswara Dental College and Hospital, Chennai, Tamil Nadu, India

Corresponding Author: A Thirumal Raj, Department of Oral Pathology and Microbiology, Sri Venkateswara Dental College and Hospital, Chennai, Tamil Nadu, India, e-mail: thirumalraj666@gmail.com

How to cite this article: Kumar SS, Sreedharan SN, Patil S, Raj AT. Potential Role of Dimers in Oncology. World J Dent 2019;10(2):83.

Source of support: Nil

Conflict of interest: None

in nature or require dimerization for activation. Their bivalent nature has made the development of dimeric and multivalent inhibitors an emerging field in anticancer drug research. ${ }^{8}$ The ability to bind to the single receptors double binding site or on to the two monomeric sites of a dimeric protein could enhance the drug potency and efficacy. Research in this area has mainly focused on natural product dimers and their analogs, and dimerized derivatives of monomers with anticancer activity. As several phase-I clinical trials have been initiated the relevance of these approaches to drug development is evident. This field will continue to expand as more natural and synthetic dimers are identified as anticancer chemotherapeutics. ${ }^{8}$

\section{References}

1. Robinson DR, Wu YM, Lin SF. The protein tyrosine kinase family of the human genome. Oncogene 2000;19:5548.

2. Schlessinger J. Cell signaling by receptor tyrosine kinases. Cell 2000;103:211.

3. Zwick E, Bange J, Ullrich A. Receptor tyrosine kinases as targets for anticancer drugs.Trends Mol Med 2002;8:17.

4. Turkson J, Kim JS, Zhang S, et al. Novel peptidomimetic inhibitors of signal transducer and activator of transcription 3 dimerization and biological activity. Cancer Ther 2004;3:261.

5. Siddiquee K, Zhang S, Guida WC, et al. Selective chemical probe inhibitor of Stat3, identified through structure-based virtual screening, induces antitumor activity. J Proc Natl Acad Sci 2007;104:7391.

6. Zhou J, Giannakakou P. Targeting microtubules for cancer chemotherapy. Curr Med Chem Anti-Cancer Agents 2005;5:65.

7. Kuppens IELM. Current state of the art of new tubulin inhibitors in the clinic. Curr Clin Pharmacol 2006;1:57-70.

8. Hadden MK, Blagg BSJ. Dimeric Approaches to Anti-Cancer Chemotherapeutics. Anticancer Agents Med Chem 2008;8(7): 807-816.

\footnotetext{
(c) The Author(s). 2019 Open Access This article is distributed under the terms of the Creative Commons Attribution 4.0 International License (https://creativecommons. org/licenses/by-nc/4.0/), which permits unrestricted use, distribution, and non-commercial reproduction in any medium, provided you give appropriate credit to the original author(s) and the source, provide a link to the Creative Commons license, and indicate if changes were made. The Creative Commons Public Domain Dedication waiver (http://creativecommons.org/publicdomain/zero/1.0/) applies to the data made available in this article, unless otherwise stated.
} 